Article

\title{
Combination of Colistin and Azidothymidine Demonstrates Synergistic Activity against Colistin-Resistant, Carbapenem-Resistant Klebsiella pneumoniae
}

\author{
Ya-Ting Chang ${ }^{1} \mathbb{C}$, Tsung-Ying Yang ${ }^{2}$, Po-Liang Lu ${ }^{1,3,4} \mathbb{C}$, Shang-Yi Lin ${ }^{1}$, Liang-Chun Wang ${ }^{5} \mathbb{D}$, \\ Sheng-Fan Wang ${ }^{2,6}{ }^{\oplus}$, Ya-Ju Hsieh ${ }^{7, *,+}$ and Sung-Pin Tseng ${ }^{2,5,6, *,+}$ \\ 1 Division of Infectious Diseases, Department of Internal Medicine, Kaohsiung Medical University Hospital, \\ Kaohsiung 807377, Taiwan; yating_iris@yahoo.com.tw (Y.-T.C.); d830166@gmail.com (P.-L.L.); \\ amoe616@gmail.com (S.-Y.L.) \\ 2 Department of Medical Laboratory Science and Biotechnology, College of Health Sciences, \\ Kaohsiung Medical University, Kaohsiung 807378, Taiwan; zegma040899@gmail.com (T.-Y.Y.); \\ wasf1234@kmu.edu.tw (S.-F.W.) \\ 3 Center for Liquid Biopsy and Cohort Research, Kaohsiung Medical University, Kaohsiung 807378, Taiwan \\ 4 School of Post-Baccalaureate Medicine, College of Medicine, Kaohsiung Medical University, \\ Kaohsiung 807378, Taiwan \\ 5 Department of Marine Biotechnology and Resources, National Sun Yat-sen University, \\ Kaohsiung 80424, Taiwan; marknjoy@g-mail.nsysu.edu.tw \\ 6 Center for Tropical Medicine and Infectious Disease Research, Kaohsiung Medical University, \\ Kaohsiung 807378, Taiwan \\ 7 Department of Medical Imaging and Radiological Sciences, Kaohsiung Medical University, \\ Kaohsiung 807378, Taiwan \\ * Correspondence: yjhsieh@kmu.edu.tw (Y.-J.H.); tsengsp@kmu.edu.tw (S.-P.T.); \\ Tel.: +886-7-3121101 (ext. 2350) (S.-P.T.) \\ + These authors contributed equally to this work.
}

Received: 12 November 2020; Accepted: 9 December 2020; Published: 11 December 2020

\begin{abstract}
Carbapenem-resistant Enterobacteriaceae (CRE) is listed as an urgent threat by the World Health Organization because of the limited therapeutic options, rapid evolution of resistance mechanisms, and worldwide dissemination. Colistin is a common backbone agent among the "last-resort" antibiotics for CRE; however, its emerging resistance among CRE has taken the present dilemma to the next level. Azidothymidine (AZT), a thymidine analog used to treat human immunodeficiency virus/acquired immunodeficiency syndrome, has been known to possess antibacterial effects against Enterobacteriaceae. In this study, we investigated the combined effects of AZT and colistin in 40 clinical isolates of colistin-resistant, carbapenem-resistant K. pneumoniae (CCRKP). Eleven of the 40 isolates harbored Klebsiella pneumoniae carbapenemase. The in vitro checkerboard method and in vivo nematode killing assay both revealed synergistic activity between the two agents, with fractional inhibitory concentration indexes of $\leq 0.5$ in every strain. Additionally, a significantly lower hazard ratio was observed for the nematodes treated with combination therapy $(0.288 ; p<0.0001)$ compared with either AZT or colistin treatment. Toxicity testing indicated potentially low toxicity of the combination therapy. Thus, the AZT-colistin combination could be a potentially favorable therapeutic option for treating CCRKP.
\end{abstract}

Keywords: Klebsiella pneumoniae; azidothymidine; Caenorhabditis elegans 


\section{Introduction}

Antimicrobial resistance (AMR) has been one of the most challenging public health problems during this era of expeditious medical advances. Multidrug-resistant organisms (MDROs) are recognized as an imminent global threat that impose substantial medical burdens and economic costs [1]. Various carbapenem-resistant Gram-negative bacteria (GNB) are listed as being critical and urgent MDRO threats by the World Health Organization and the US Centers for Disease Control and Prevention (CDC) $[2,3]$ because of the rapid evolution of their resistance mechanisms and worldwide dissemination. Globally, the prevalence rates of carbapenem-resistant Enterobacteriaceae (CRE) have been increasing, especially those of Klebsiella pneumoniae and Escherichia coli [4]. Because of the limited antimicrobial options and an increased risk for horizontal transmission due to the presence of resistance genes in mobile genetic elements, the treatment and containment of CRE infections have become serious dilemmas in daily practice and in terms of infection control [5].

The phenotypic resistance to carbapenems in CRE typically originates from two main mechanisms: (1) the combined effects of $\beta$-lactamase(s) and structural mutations, and (2) the production of carbapenemases [6]. Therefore, $\mathrm{CRE}$ is frequently categorized into carbapenemase-producing (CP) CRE (CP-CRE) and non-CP CRE (non-CP-CRE). CP-CRE exhibits higher carbapenem minimum inhibitory concentrations (MICs), results in higher mortality, and has an increased risk for resistance transmission [7,8]. CP-K. pneumoniae (CPKP) is the most widely reported CRE species, with a much higher and increasing prevalence compared with E. coli [9]. Therefore, CPKP is the most extensively studied CRE regarding treatment response to various new and old antibiotics.

Among the list of "old antibiotics" for emerging MDROs, polymyxin B and E (colistin) are frequently used as the backbone of combination therapy for CRE [10]. In countries or regions where new $\beta$-lactam/ $\beta$-lactamase inhibitors (BLBLIs) are unavailable, colistin resistance in CRE has a significant impact on patient survival [11]. In such a difficult situation, combining colistin with a synergistic agent would be a potential option and feasible approach. Azidothymidine (AZT; $3^{\prime}$-azido-3'-deoxythymidine), and also known as zidovudine, is a thymidine analog used as an antiretroviral agent to treat human immunodeficiency virus/acquired immunodeficiency syndrome (HIV/AIDS). It has been found to possess antibacterial effects against GNB [12-14]. Several studies that were conducted to repurpose screens among FDA-approved drugs showed that AZT is a potential candidate for combination therapy of multidrug-resistant GNB, including CRE [14-16].

In this study, we performed synergistic analyses between AZT and colistin on 40 isolates of colistin-resistant, carbapenem-resistant K. pneumoniae (CCRKP) by using the checkerboard method. Meanwhile, an animal model using Caenorhabditis elegans was applied to evaluate the in vivo efficacy and safety of combination therapy. To the best of our knowledge, this study is the first to examine AZT-colistin synergism for concomitant colistin- and carbapenem-resistant K. pneumoniae isolates.

\section{Materials and Methods}

\subsection{Bacterial Isolates}

As a part of Taiwan's nationwide surveillance, 40 isolates of CCRKP were collected between 2013 and 2015 from 11 hospitals in Taiwan [9,17]. Carbapenem resistance was defined as resistance to either imipenem or meropenem, according to the Clinical and Laboratory Standards Institute (CLSI) guidelines [18]. Colistin resistance was defined as MIC $>2 \mu \mathrm{g} / \mathrm{mL}$, according to the European Committee on Antimicrobial Susceptibility Testing (EUCAST) criteria [19]. Among the 40 isolates, urine was the main source $(11 / 40,27.5 \%)$, followed by sputum $(10 / 40,25 \%)$, stool $(4 / 40,10 \%)$, pus/wound $(3 / 40,7.5 \%)$, abscess $(3 / 40,7.5 \%)$, blood $(2 / 40,5 \%)$, endotracheal aspirate $(2 / 40,5 \%)$, ascites $(2 / 40,5 \%)$, bile $(2 / 40,5 \%)$, and drainage $(1 / 40,2.5 \%)$ (Table 1$)$. 
Table 1. Sources of the 40 isolates.

\begin{tabular}{cc}
\hline Source & No. of Isolates \\
\hline Urine & 11 \\
Sputum & 10 \\
Stool & 4 \\
Pus/wound & 3 \\
Abscess & 3 \\
Blood & 2 \\
Endotracheal & 2 \\
Ascites & 2 \\
Bile & 2 \\
Drainage & 1 \\
\hline
\end{tabular}

\subsection{Antimicrobial Susceptibility}

The broth microdilution method (Sensititre, Trek Diagnostic Systems, Cleveland, OH, USA) was used to determine the isolates' susceptibility profiles against 18 antimicrobial agents, according to the CLSI guidelines [18], including $\beta$-lactams (ampicillin, ceftazidime, cefazolin, cefepime, cefoxitin, ceftriaxone, imipenem, meropenem, doripenem, ertapenem, cefotaxime, and piperacillin-tazobactam), monobactams (aztreonam), aminoglycosides (amikacin and gentamicin), quinolones (ciprofloxacin and levofloxacin), and folate inhibitors (trimethoprim/sulfamethoxazole). For tigecycline and colistin, the Enterobacteriaceae breakpoints were adopted, according to the Food and Drug Administration (FDA) and EUCAST guidelines, respectively. Furthermore, a standard broth microdilution method was applied in accordance with CLSI guidelines to evaluate the MICs for colistin and AZT.

\subsection{Synergistic Analysis}

The synergism between AZT and colistin was investigated through the checkerboard method, as described previously [20]. In brief, the bacterial suspension of each strain was prepared in cation-adjusted Mueller-Hinton broth (CAMHB) and was added to wells at a final concentration of $5 \times 10^{5} \mathrm{CFU} / \mathrm{mL}$. Two-fold serial dilutions of AZT and colistin were prepared and added to the wells containing bacteria. The synergistic effects were determined according to the fractional inhibitory concentration (FIC) index, which was calculated as follows:

(MIC of drug A tested in combination)/(MIC of drug A tested alone) + (MIC of drug B tested in combination)/(MIC of drug B tested alone).

Synergy is defined as an FIC index $\leq 0.5$. An FIC index between 0.5 and 4.0 is interpreted as there being no interaction, and antagonism is defined as an FIC index of $>4$.

\subsection{In Vivo Study}

C. elegans, strain N2, was used for both in vivo toxicity and nematode-killing assays. Nematode growth medium (NGM) agar plates with bacterial lawns of E. coli, laboratory strain OP50, were used as food sources for the maintenance of nematodes at $20^{\circ} \mathrm{C}$. The procedures were carried out as described in our previous study [21]. NGM agar plates were prepared with the following antibiotic concentrations: colistin, $1 \mu \mathrm{g} / \mathrm{mL}$; AZT, $0.15 \mu \mathrm{g} / \mathrm{mL}$; a combination of colistin and AZT, 1 and $0.15 \mu \mathrm{g} / \mathrm{mL}$, respectively. Clinical isolates of CCRKP strain 1336 or E. coli OP50 were spread onto the plates. Growth-synchronized L4-stage nematodes (40 for each group) were transferred onto the plates containing different antimicrobial agents and bacterial lawns. All plates were maintained at $25{ }^{\circ} \mathrm{C}$, and the survival of nematodes was recorded daily. For the toxicity assay, treatment plates that were supplemented with a vehicle served as the controls. For the killing assay, the plates containing only a lawn of $E$ coli OP50 served as the negative control. 


\subsection{Polymerase Chain Reaction Detection}

Polymerase chain reactions were used to detect the presence of extended-spectrum $\beta$-lactamase (ESBL) genes (bla $a_{\mathrm{SHV}}, b l a_{\mathrm{TEM}}, b l a_{\mathrm{OXA}}, b l a_{\mathrm{CTX}-\mathrm{M}-\mathrm{G} 1}, b l a_{\mathrm{CTX}-\mathrm{M}-\mathrm{G} 2}$, and $\left.b l a_{\mathrm{CTX}-\mathrm{M}-\mathrm{G} 9}\right)$, plasmid-mediated AmpC genes ( $b l a_{\mathrm{DHA}}$ and $\left.b l a_{\mathrm{CMY}}\right)$, carbapenemase genes (bla $a_{\mathrm{KPC}}, b l a_{\mathrm{NDM}}, b l a_{\mathrm{IMP}}, b l a_{\mathrm{NMC}}, b l a_{\mathrm{SME}}, b l a_{\mathrm{VIM}}$, $b l a_{\mathrm{SPM}-1}, b l a_{\mathrm{GIM}-1}, b l a_{\mathrm{SIM}-1}, b l a_{\mathrm{IMI}}, b l a_{\mathrm{GES}}$, and $\left.b l a_{\mathrm{OXA}-48}\right), m c r-1$ gene and outer membrane porin genes (ompK35 and ompK36) (Table S1) [21]. Reactions were performed using TaKaRa Taq ${ }^{\mathrm{TM}}$ (Cat. R001A, Takara Shuzo Co., Ltd., Tokyo, Japan) and prepared in a total volume of $25 \mu \mathrm{L}$, in accordance with the instruction manual. All analyses were performed with corresponding positive controls.

\subsection{Statistical Analyses}

The MIC distributions of colistin and AZT, in combination or alone, were constructed with GraphPad Prism software (v.7.0) and analyzed using paired Student's t-tests.

\section{Results}

\subsection{Distribution of Resistance Mechanisms and In Vitro Susceptibilities}

Among the 40 isolates of CCRKP, Klebsiella pneumoniae carbapenemase (KPC) was identified in 11 of them and was the only carbapenemase. None of the strains harbored the mcr 1 gene. For non-CP-CCRKP, $51.7 \%(15 / 29)$ had more than three types of resistance mechanisms, which most commonly involved DHA AmpC $\beta$-lactamase gene (20 isolates) and ESBL genes (TEM, 17 isolates; CTX-M, 15 isolates) (Figure 1a). It was determined that all except one isolate of CP-CCRKP had lost OmpK36 (Figure 1b). The antimicrobial susceptibilities to 19 common antimicrobial agents are listed in Table 2; tigecycline and amikacin demonstrated higher susceptibilities of $87.5 \%$ and $70 \%$, respectively, compared with the other antimicrobials tested. The MICs for colistin ranged from 4 to $12 \mu \mathrm{g} / \mathrm{mL}$, with the $\mathrm{MIC}_{50}$ being $64 \mu \mathrm{g} / \mathrm{mL}$ and $\mathrm{MIC}_{90}$ being $128 \mu \mathrm{g} / \mathrm{mL}$. The MICs for AZT ranged from 0.125 to $16 \mu \mathrm{g} / \mathrm{mL}$, with the $\mathrm{MIC}_{50}$ being $1 \mu \mathrm{g} / \mathrm{mL}$ and $\mathrm{MIC}_{90}$ being $2 \mu \mathrm{g} / \mathrm{mL}$ (Table 3). Table 3 also shows the changes to MICs after the two drugs were combined. MICs for both AZT and colistin decreased significantly after combining with the respective drug, ranging from 1 to $2 \mu \mathrm{g} / \mathrm{mL}$ for AZT and 0.03125 to $1 \mu \mathrm{g} / \mathrm{mL}$ for colistin. Figure 2 presents a comparison of the MICs of AZT and colistin as single agents and in combination. After combination, the MIC values of colistin fell below the breakpoint for resistance (MIC $\leq 2 \mu \mathrm{g} / \mathrm{mL}$ ) in all strains. Moreover, the mean MIC value of AZT attained an average steady-state serum concentration of $0.19 \mu \mathrm{g} / \mathrm{mL}$ after combination with colistin [22].

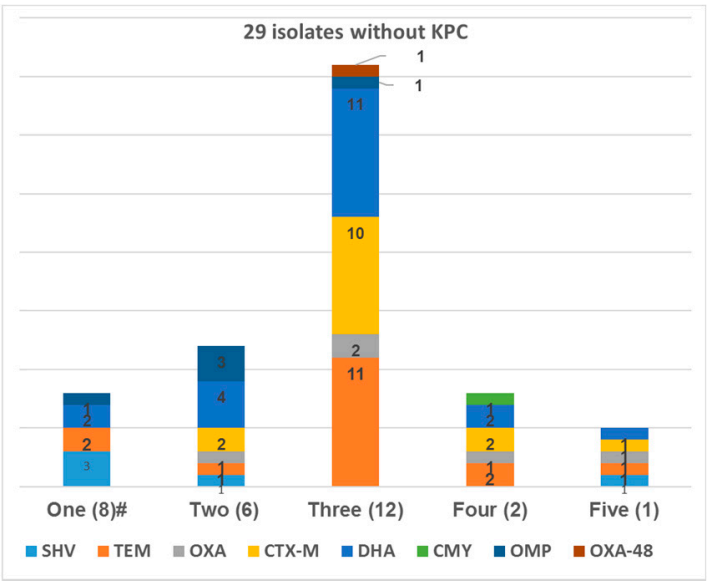

(a)

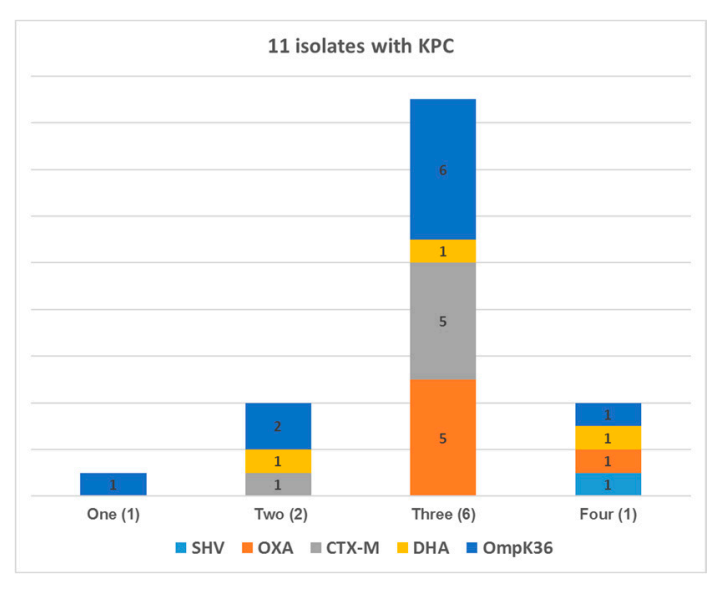

(b)

Figure 1. Distribution of the examined resistance mechanisms among the 40 isolates. (a) non-KPC producers; \#, number of simultaneous resistance mechanisms (number of isolates) (b) KPC producers, with one isolate lacking data for outer membrane proteins. 
Table 2. Antimicrobial susceptibilities against 19 common antimicrobial agents.

\begin{tabular}{cccc}
\hline \multirow{2}{*}{ Antimicrobial Agents } & \multicolumn{3}{c}{ Antibiotic Susceptibility } \\
\cline { 2 - 4 } & $\mathbf{S}$ & $\mathbf{I}$ & $\mathbf{R}$ \\
\hline Ampicillin & $0.0 \%$ & $0.0 \%$ & $100.0 \%$ \\
Ceftazidime & $0.0 \%$ & $2.5 \%$ & $97.5 \%$ \\
Cefazolin & $0.0 \%$ & $0.0 \%$ & $100.0 \%$ \\
Cefepime & $5.0 \%$ & $7.5 \%$ & $87.5 \%$ \\
Cefoxitin & $2.5 \%$ & $2.5 \%$ & $95.0 \%$ \\
Ceftriaxone & $0.0 \%$ & $0.0 \%$ & $100.0 \%$ \\
Cefotaxime & $2.5 \%$ & $0.0 \%$ & $97.5 \%$ \\
Imipenem & $2.5 \%$ & $10.0 \%$ & $87.5 \%$ \\
Meropenem & $7.5 \%$ & $0.0 \%$ & $92.5 \%$ \\
Doripenem & $7.5 \%$ & $2.5 \%$ & $90.0 \%$ \\
Ertapenem & $0.0 \%$ & $2.5 \%$ & $97.5 \%$ \\
Aztreonam & $7.5 \%$ & $2.5 \%$ & $90.0 \%$ \\
Piperacillin/Tazobactam & $5.0 \%$ & $0.0 \%$ & $95.0 \%$ \\
Tigecycline & $87.5 \%$ & $10.0 \%$ & $2.5 \%$ \\
Ciprofloxacin & $2.5 \%$ & $0.0 \%$ & $97.5 \%$ \\
Levofloxacin & $2.5 \%$ & $0.0 \%$ & $97.5 \%$ \\
Gentamicin & $32.5 \%$ & $0.0 \%$ & $67.5 \%$ \\
Amikacin & $70.0 \%$ & $0.0 \%$ & $30.0 \%$ \\
Sulfamethoxazole-Trimethoprim & $12.5 \%$ & $0.0 \%$ & $87.5 \%$ \\
\hline
\end{tabular}

Table 3. MIC range, $\mathrm{MIC}_{50}, \mathrm{MIC}_{75}$, and $\mathrm{MIC}_{90}$ for colistin, $\mathrm{AZT}$, and colistin/AZT combination.

\begin{tabular}{ccccccccc}
\hline \multirow{2}{*}{ Agents } & \multicolumn{4}{c}{ MIC $(\mu \mathrm{g} / \mathrm{mL})$} & \multicolumn{3}{c}{ MIC in Combination $(\mu \mathrm{g} / \mathrm{mL})$} \\
\cline { 2 - 11 } & Range & $\mathbf{M I C}_{\mathbf{5 0}}$ & $\mathbf{M I C}_{\mathbf{7 5}}$ & $\mathbf{M I C}_{\mathbf{9 0}}$ & Range & MIC $_{\mathbf{5 0}}$ & MIC $_{\mathbf{7 5}}$ & MIC $_{\mathbf{9 0}}$ \\
\hline Colistin & $4-512$ & 64 & 64 & 128 & $1-2$ & 1 & 1 & 2 \\
AZT & $0.125-16$ & 1 & 2 & 2 & $0.03125-1$ & 0.125 & 0.125 & 0.25 \\
\hline
\end{tabular}

MIC, minimum inhibitory concentration; AZT, azidothymidine.

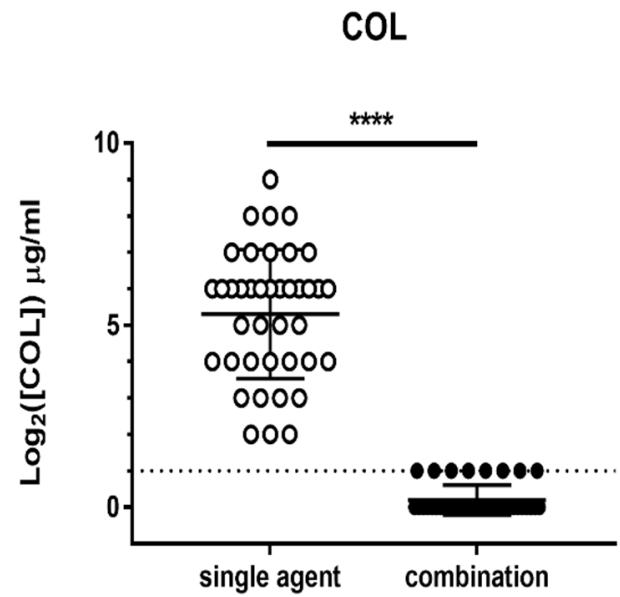

(a)

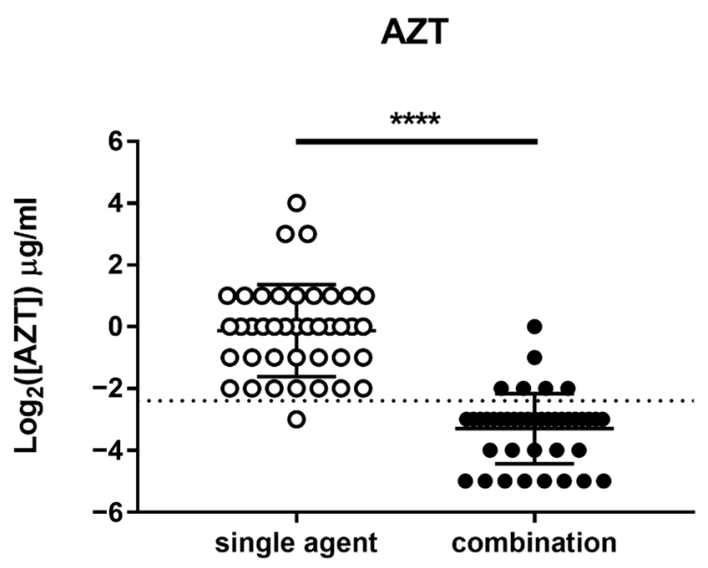

(b)

Figure 2. MIC distributions of colistin (COL, hollow circles), azidothymidine (AZT, hollow circles), and their combination (filled circles). (a) Dotted line indicates the breakpoint for colistin resistance according to the EUCAST guidelines. (b) Dotted line represents the average steady-state concentration of AZT in plasma $(0.19 \mu \mathrm{g} / \mathrm{mL}){ }^{* * * *}, p<0.0001$ with the paired $t$-test. 


\subsection{Checkerboard Analysis and In Vivo C. elegans Toxicity and Killing Assay}

To determine the combined effects of colistin and AZT, the checkerboard method was utilized and demonstrated synergistic activity (Table 4). The FIC indexes were $\leq 0.5$ for $100 \%$ of both KPC producers and nonproducers, clearly showing synergism in the 40 strains of CCRKP, regardless of carbapenemase production (all KPC in this study).

Table 4. In vitro synergistic analysis using the checkerboard method.

\begin{tabular}{ccccc}
\hline \multicolumn{1}{c}{ Group } & $\begin{array}{c}\text { Activity of the } \\
\text { Combination }\end{array}$ & FICI Criteria & Total No. (\%) of Isolates \\
\hline \multirow{4}{*}{ CCRKP $(\mathrm{n}=40)$} & KPC-producer & synergy & $\leq 0.5$ & $11(100.0 \%)$ \\
& $(\mathrm{n}=11)$ & No interaction & $>0.5-4$ & 0 \\
& Antagonism & $>4$ & 0 \\
\cline { 2 - 5 } & non-KPC-producer & synergy & $\leq 0.5$ & $29(100.0 \%)$ \\
$(\mathrm{n}=29)$ & No interaction & $>0.5-1$ & 0 \\
& Antagonism & $>4$ & 0 \\
\hline
\end{tabular}

FICI, fractional inhibitory concentration index; KPC, Klebsiella pneumoniae carbapenemase.

For the toxicity testing of colistin, AZT, and their combination, C. elegans were fed with E. coli OP50 and treated with different regimens. As shown in Figure 3 and Table 5, no differences were observed between the groups of nematodes treated with colistin, AZT, or a combination thereof compared with the E. coli OP50 control group. This result suggests that the combination of AZT and colistin is safe. In addition, the synergistic activity between AZT and colistin was confirmed using the nematode killing assay. C. elegans fed with nontoxic E. coli OP50 (OP50-control) had a significantly longer median survival time (9 days; $p<0.0001)$ compared with $C$. elegans infected with a clinical strain of K. pneumoniae 1336 (1336-control) (Figure 4 and Table 5). There were no significant differences found between the 1336-control and the nematodes treated with either colistin at $1 \mu \mathrm{g} / \mathrm{mL}$ or AZT at $0.15 \mu \mathrm{g} / \mathrm{mL}$, implying that neither of the antimicrobial agents could rescue the nematodes infected with a CCRKP. By contrast, the infected nematodes that were treated with a combination of colistin and AZT had a medium survival time that was significantly extended, from 6 days to 8.5 days $(p<0.0001)$. A significantly lower hazard ratio (HR) was observed for the nematodes treated with combination therapy (HR, $0.288 ; 95 \%$ confidence interval 0.17 to $0.50 ; p<0.0001$ ).

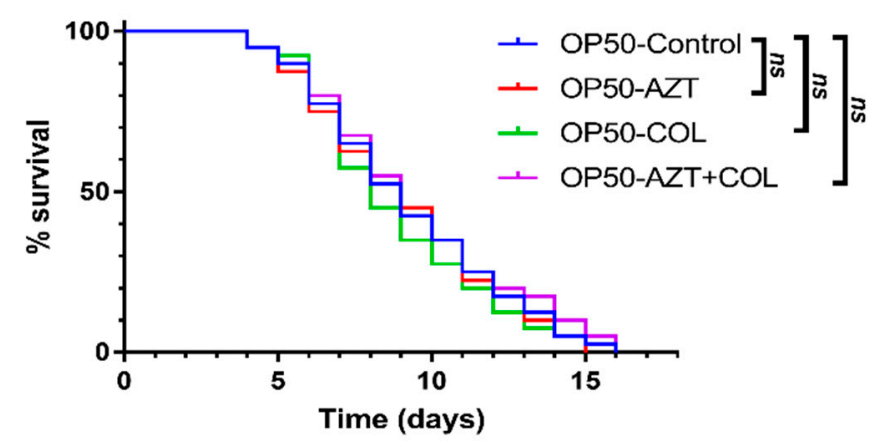

Figure 3. In vivo toxicity testing of colistin, AZT, or colistin/AZT combination using a C. elegans model. Nematodes ( $\mathrm{n}=40$, each group) were fed with nontoxic E. coli laboratory strain OP50 and supplemented with a vehicle (control), colistin (COL, at $1 \mu \mathrm{g} / \mathrm{mL}$ ), azidothymidine (AZT, at $0.15 \mu \mathrm{g} / \mathrm{mL}$ ), or a combination (AZT + COL, at $0.15 / 1 \mu \mathrm{g} / \mathrm{mL}$ ). ns, no significance. 
Table 5. Statistical analyses of in vivo C. elegans toxicity testing and killing assays.

\begin{tabular}{ccccccc}
\hline \multirow{2}{*}{ Test } & Group & $\begin{array}{c}\text { Median Survival } \\
\text { (Days) }\end{array}$ & $p$ Value & Risk Ratio & \multicolumn{2}{c}{$\mathbf{9 5 \%}$ CI } \\
\hline \multirow{2}{*}{ In vivo } & OP50-Control & 9 & - & 1 & - & - \\
toxicity assay & OP50-AZT & 9 & 0.7901 & 0.934 & 0.57 & 1.54 \\
& OP50-COL & 8 & 0.4573 & 0.827 & 0.50 & 1.36 \\
& OP50-AZT + COL & 9 & 0.6177 & 1.13 & 0.69 & 1.87 \\
\hline \multirow{2}{*}{ In vivo } & OP50-Control & 9 & $<0.0001$ & 0.27 & 0.16 & 0.47 \\
killing assay & 1336-Control & 6 & - & 1 & - & - \\
& 1336-AZT & 6 & 0.7254 & 1.097 & 0.65 & 1.84 \\
& 1336-COL & 6 & 0.8561 & 0.953 & 0.56 & 1.61 \\
& 1336-AZT + COL & 8.5 & $<0.0001$ & 0.288 & 0.17 & 0.50 \\
\hline
\end{tabular}

OP50, laboratory strain of nontoxic Escherichia coli OP50 as a food source for nematodes (representing the negative control); COL, colistin (concentration of $1 \mu \mathrm{g} / \mathrm{mL}$ ); AZT, azidothymidine (concentration of $0.15 \mu \mathrm{g} / \mathrm{mL}$ ); AZT + COL, combination (concentration of $0.15 / 1 \mu \mathrm{g} / \mathrm{mL}$ ); 1336, clinical isolate of CCRKP; CI, confidence interval.

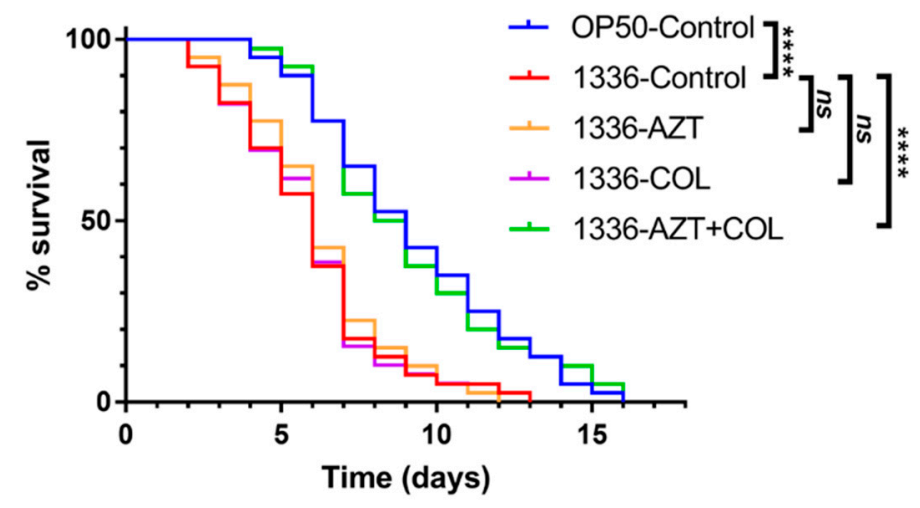

Figure 4. In vivo killing assay of CCRKP strain 1336 using a C. elegans model. Forty nematodes were infected with CCRKP clinical strain 1336 (isolated from blood) and supplemented with a vehicle (control), colistin (COL, at $1 \mu \mathrm{g} / \mathrm{mL}$ ), azidothymidine (AZT, at $0.15 \mu \mathrm{g} / \mathrm{mL}$ ), or a combination $(\mathrm{AZT}+\mathrm{COL}$, at $0.15 / 1 \mu \mathrm{g} / \mathrm{mL})$. ns, no significance; ${ }^{* * * *}, p<0.0001$.

\section{Discussion}

CRE has become an imminent global hazard with increasing prevalence worldwide, leading to increased healthcare costs and higher mortality [23]. Among the carbapenemases with a high risk for transmission, KPC is the most prevalent and widely spread [24]. Despite the introduction of novel BLBLIs on the market in recent years, such as ceftazidime/avibactam, imipenem/relebactam, and meropenem/vaborbactam, polymyxins remain an important agent for the treatment of CRE, especially in regions where the new BLBLIs are unavailable or prevalent with metallo- $\beta$-lactamases-producing CRE. Nevertheless, the emerging resistance of CRE against "last-resort" antibiotics, such as colistin, tigecycline, and fosfomycin, has been increasingly reported [11,25-27]. The emergence of the colistin resistance gene $m c r 1$ in CRE is of great concern, especially with its potential to spread into geographical areas beyond China and Southeast Asia, where it is most frequently reported, and into Enterobacteriaceae species other than E. coli and K. pneumoniae [28,29].

In this study, the mor 1 gene was not detected in any of the 40 clinical isolates of CCRKP. The extensive resistance primarily comes from the combination of multiple extensive-spectrum $\beta$-lactamases or carbapenemase (all KPC), predominantly combined with outer membrane protein deficiency (all Omp36K). AZT alone demonstrated relatively low MICs for the CCRKP (Table 3), and a similar observation was reported by Peyclit et al. for one strain of colistin-resistant, carbapenem-resistant K. pneumoniae, with AZT being highly effective at an MIC of $0.104 \mu \mathrm{g} / \mathrm{mL}$ [14]. Among the 12 strains of isolates with relatively higher AZT MICs, ranging from 2 to $16 \mu \mathrm{g} / \mathrm{mL}$ (nine isolates at $2 \mu \mathrm{g} / \mathrm{mL}$, 
two isolates at $8 \mu \mathrm{g} / \mathrm{mL}$, one isolate at $16 \mu \mathrm{g} / \mathrm{mL}$; data not shown), only two strains harbored KPC, both with MICs at $2 \mu \mathrm{g} / \mathrm{mL}$. Notably, all KPC-producing strains had lower MICs for AZT $(0.25-2 \mu \mathrm{g} / \mathrm{mL})$. Among the three isolates that exhibited the highest MICs for AZT, two had only one resistance gene $(\mathrm{SHV}(\mathrm{MIC}=8)$ and DHA $(\mathrm{MIC}=16))$, and one had multiple $\beta$-lactamase genes (TEM, DHA, and CTX-M (MIC = 8)). This observation is reasonable considering that the resistance mechanisms of AZT appear to involve the loss of thymidine kinase activity and/or poor cell membrane permeation $[30,31]$ instead of the more commonly known mechanisms of $\beta$-lactamases. This suggests that AZT could be a favorable therapeutic candidate, even for carbapenemase-producing organisms.

We demonstrated the evident synergy between AZT and colistin using the checkerboard method (Table 4) and nematode killing assay (Table 5). The synergistic activity of polymyxins and AZT among E. coli and K. pneumoniae carrying various resistance mechanisms (Table 6) has been reported in several previous studies [32-35]. The most commonly investigated resistance genotypes are $m c r 1$ and $b l a_{\mathrm{NDM}-1}$. This study is the first to examine the combined effects of AZT and colistin in Enterobacteriaceae with concomitant colistin and carbapenem resistance. It also bears the important clinical implication that the colistin MIC in these 40 isolates decreased dramatically to a range of $1-2 \mu \mathrm{g} / \mathrm{mL}$ after combination with AZT, which is defined as susceptible by the EUCAST guidelines. AZT is a thymidine analog that acts as an inhibitor of HIV reverse transcriptase. Before being adopted as the first antiretroviral drug for HIV/AIDS, it had been noted to exhibit potent in vitro bactericidal activity against various bacteria of the family Enterobacteriaceae [36]. In Enterobacteriaceae, AZT is phosphorylated by thymidine kinase (when present) to its triphosphate metabolites, which are then incorporated into the bacterial DNA chain as a replication terminator [36]. Nonfermenters, such as Pseudomonas and Acinetobacter species, are unaffected by AZT because they naturally lack thymidine kinase [37]. In addition to the thymidine kinase levels of the bacteria, AZT susceptibility also correlates to cell permeability. Given that colistin lyses GNB by permeabilizing the outer membrane, it is hypothesized that this mechanism allows AZT to enter the cell at increased intracellular drug concentrations [38]. Lin et al. demonstrated that higher polymyxin B concentrations could increase outer membrane permeability, with simultaneous decreases in AZT MIC [33]. In addition, AZT can synergize with colistin by exerting a shared outer membrane disrupting effect [38].

Table 6. Combination therapy against Enterobacteriaceae in different countries.

\begin{tabular}{|c|c|c|c|c|c|c|c|c|c|}
\hline \multirow{2}{*}{ Species } & \multirow{2}{*}{ Country } & \multirow{2}{*}{ No. } & \multirow{2}{*}{$\begin{array}{l}\text { Resistance } \\
\text { Phenotype }\end{array}$} & \multirow{2}{*}{$\begin{array}{c}\text { Resistance } \\
\text { Mechanism(s) }\end{array}$} & \multicolumn{2}{|c|}{ MIC of AZT (mg/L) } & \multicolumn{2}{|c|}{ MIC of Colistin (mg/L) } & \multirow[t]{2}{*}{ Ref. } \\
\hline & & & & & Alone & Combination & Alone & Combination & \\
\hline K. pneumoniae & Greece & 100 & Colistin & NA & $0.125-4$ & $0.0625-1$ & $4-128$ & $0.25-16$ & [34] \\
\hline E. coli & China & 9 & $\begin{array}{l}\text { Colistin } \\
\text { and } \\
\text { tigecycline }\end{array}$ & $\begin{array}{l}\text { tet }(\mathrm{X}) \text { and } \\
m c r-1\end{array}$ & $0.5-4$ & $0.3-1.5$ & $4-8$ & $<0.13-4$ & [32] \\
\hline $\begin{array}{l}\text { K. pneumoniae, } \\
\text { E. coli, E. cloacae }\end{array}$ & UK & 7 & Carbapenem & $b l a_{\mathrm{NDM}-1}$ & $2-4$ & \multirow{2}{*}{$0.25-16$} & $0.125-1$ & $\begin{array}{c}\text { Reduced } \\
32-256 \text { fold }\end{array}$ & [35] \\
\hline E. coli & UK & 13 & Colistin & $m c r-1$ & $8-64$ & & $2-8$ & $\begin{array}{l}\text { Reduced } \\
4-256 \text { fold }\end{array}$ & [35] \\
\hline K. pneumoniae & Taiwan & 40 & $\begin{array}{c}\text { Colistin } \\
\text { and } \\
\text { carbapenem }\end{array}$ & $\begin{array}{l}\text { multiple, } \\
\text { bla }_{\mathrm{KPC}}\end{array}$ & $0.125-16$ & $0.03125-1$ & $4-512$ & $1-2$ & $\begin{array}{c}\text { Present } \\
\text { study }\end{array}$ \\
\hline
\end{tabular}

NA: not available; tet $(\mathrm{X})$, a unique mobile tigecycline resistance gene [32].

The peak plasma AZT concentration (Cmax) of $1-5 \mu \mathrm{g} / \mathrm{mL}$ is achieved approximately $1 \mathrm{~h}$ after ingestion of 200-300 mg of AZT [39-42]. The pharmacokinetics (PK) of AZT has been most extensively investigated among HIV-infected individuals. In the works of Drew et al. [41] and Burger et al. [40], among HIV-infected patients, a Cmax of $0.73-1.3$ and $0.8-1.1 \mu \mathrm{g} / \mathrm{mL}$ could be attained at 0.76 and $0.77 \mathrm{~h}$, respectively. Wattanagoon et al. reported a Cmax of $17.98 \mu \mathrm{M}(4.8 \mu \mathrm{g} / \mathrm{mL})$ in healthy volunteers in Thailand after a single ingested dose of $300 \mathrm{mg}$ AZT [39]. In agreement with a recent study [34], we found relatively low AZT MICs $(0.03125-1 \mu \mathrm{g} / \mathrm{mL})$ for colistin-resistant K. pneumoniae after combination with colistin, indicating that AZT could be a practical therapeutic candidate because of its clinically 
achievable concentrations. Loose et al. [37] investigated the serum bactericidal activity of combined intravenous (IV) colistin methanesulfonate (CMS) and AZT in colistin-resistant GNB (five isolates of mcr1-harboring E. coli). The trial was part of a phase 1 randomized, double-blinded study in healthy volunteers receiving multiple doses of IV CMS coadministrated with AZT. Seven volunteers received three IV infusions consisting of the following: first infusion, 4 million international units (MIU) of CMS and $200 \mathrm{mg}$ of AZT; second and third infusions, 2 MIU of CMS and $100 \mathrm{mg}$ of AZT. The study found the combination to be well tolerated, with only transient and manageable gastrointestinal side effects. It also revealed bactericidal, or at least bacteriostatic, activities for all strains tested. The results obtained with our in vivo C. elegans toxicity testing model are consistent with those reported by Loose et al. [37]. Although AZT appears to be important in the combined treatment of MDROs, the rapid emergence of stable high-level AZT resistance in Enterobacteriaceae has been well documented, which appears to be related to the loss of thymidine kinase activity [30,43]. Lin et al. demonstrated that the combination of polymyxin B and AZT has superior antimicrobial efficacy and minimizes the emergence of resistance to polymyxins [33]. The two-drug combination significantly increased bacterial killing and remained synergistic for up to $48 \mathrm{~h}$ in their study. It also significantly delayed bacterial regrowth compared with either monotherapy.

\section{Conclusions}

This study demonstrates the evident synergy between colistin and AZT in 40 clinical CCRKP isolates, regardless of the presence of carbapenemase. In vivo toxicity testing indicated low toxicity of the two-drug combination. The combined treatment also significantly increased the lifespan of C. elegans in the nematode killing assay. According to our findings, AZT could serve as a promising component in a combination regimen for CRE treatment. AZT has many beneficial characteristics, such as intravenous formulation, attainable clinical plasma concentration with effective central nervous system penetration, and known safety profiles for a wide range of populations, such as neonates or children and pregnant women. The AZT/colistin combination could be a potential therapeutic option for the treatment of CCRKP. Future investigation into the optimal dosage and frequency is necessary to achieve clinical efficacy and prevent the rapid emergence of resistance.

Supplementary Materials: The following are available online at http://www.mdpi.com/2076-2607/8/12/1964/s1, Table S1: Primers used in for PCR detection of antibiotic resistant genes.

Author Contributions: Conceptualization, Y.-J.H. and S.-P.T.; methodology, T.-Y.Y. and L.-C.W.; software, T.-Y.Y.; validation, T.-Y.Y., P.-L.L. and S.-Y.L.; formal analysis, Y.-T.C. and S.-F.W.; investigation, Y.-T.C. and T.-Y.Y.; resources, Y.-J.H. and S.-P.T.; data curation, Y.-J.H. and S.-P.T.; writing-original draft preparation, Y.-T.C., T.-Y.Y. and S.-P.T.; writing-review and editing, Y.-T.C. and S.-P.T.; visualization, S.-P.T.; supervision, Y.-J.H. and S.-P.T.; project administration, S.-P.T.; funding acquisition, Y.-J.H. and S.-P.T. All authors have read and agreed to the published version of the manuscript.

Funding: This work was supported by grants from Ministry of Science and Technology of Taiwan (MOST 109-2320-B-037-027), Kaohsiung Medical University Research Foundation (M109001), Kaohsiung Medical University Research Center Grant (KMU-TC109B02), and National Sun Yat-sen University-Kaohsiung Medical University (NSYSU-KMU) Joint Research Project (NSYSUKMU 109-I005).

Conflicts of Interest: The authors declare no conflict of interest.

\section{References}

1. Marston, H.D.; Dixon, D.M.; Knisely, J.M.; Palmore, T.N.; Fauci, A.S. Antimicrobial Resistance. JAMA 2016, 316, 1193-1204. [CrossRef] [PubMed]

2. Global Priority List of Antibiotic-Resistant Bacteria to Guide Research, Discovery, and Development of New Antibiotics. Available online: https://www.who.int/medicines/publications/global-priority-list-antibioticresistant-bacteria/en/ (accessed on 11 November 2020).

3. 2019 AR Threats Report. Available online: https://www.cdc.gov/drugresistance/biggest-threats.html? CDC_AA_refVal=https $\% 3 \mathrm{~A} \% 2 \mathrm{~F} \% 2 \mathrm{Fwww} . c d c . g o v \% 2 F d r u g r e s i s t a n c e \% 2 F b i g g e s t$ threats.html (accessed on 11 November 2020). 
4. Kelly, A.M.; Mathema, B.; Larson, E.L. Carbapenem-resistant Enterobacteriaceae in the community: A scoping review. Int. J. Antimicrob. Agents 2017, 50, 127-134. [CrossRef] [PubMed]

5. Logan, L.K.; Weinstein, R.A. The epidemiology of carbapenem-resistant Enterobacteriaceae: The impact and evolution of a global menace. J. Infect. Dis. 2017, 215, S28-S36. [CrossRef] [PubMed]

6. Bush, K.; Fisher, J.F. Epidemiological expansion, structural studies, and clinical challenges of new beta-lactamases from gram-negative bacteria. Annu. Rev. Microbiol. 2011, 65, 455-478. [CrossRef] [PubMed]

7. Lasko, M.J.; Nicolau, D.P. Carbapenem-resistant Enterobacterales: Considerations for treatment in the era of new antimicrobials and evolving enzymology. Curr. Infect. Dis. Rep. 2020, 22, 6. [CrossRef] [PubMed]

8. Tamma, P.D.; Goodman, K.E.; Harris, A.D.; Tekle, T.; Roberts, A.; Taiwo, A.; Simner, P.J. Comparing the outcomes of patients with carbapenemase-producing and non-carbapenemase-producing carbapenem-resistant Enterobacteriaceae bacteremia. Clin. Infect. Dis. 2017, 64, 257-264. [CrossRef]

9. Chang, Y.T.; Siu, L.K.; Wang, J.T.; Wu, T.L.; Chen, Y.H.; Chuang, Y.C.; Lin, J.C.; Lu, P.L. Resistance mechanisms and molecular epidemiology of carbapenem-nonsusceptible Escherichia coli in Taiwan, 2012-2015. Infect. Drug Resist. 2019, 12, 2113-2123. [CrossRef]

10. Rodriguez-Bano, J.; Gutierrez-Gutierrez, B.; Machuca, I.; Pascual, A. Treatment of infections caused by extended-spectrum-beta-lactamase-, ampC-, and carbapenemase-producing Enterobacteriaceae. Clin. Microbiol. Rev. 2018, 31. [CrossRef]

11. Rojas, L.J.; Salim, M.; Cober, E.; Richter, S.S.; Perez, F.; Salata, R.A.; Kalayjian, R.C.; Watkins, R.R.; Marshall, S.; Rudin, S.D.; et al. Colistin resistance in carbapenem-resistant Klebsiella pneumoniae: Laboratory detection and impact on mortality. Clin. Infect. Dis. 2017, 64,711-718. [CrossRef]

12. Keith, B.R.; White, G.; Wilson, H.R. In vivo efficacy of zidovudine (3'-azido-3'-deoxythymidine) in experimental gram-negative-bacterial infections. Antimicrob. Agents Chemother. 1989, 33, 479-483. [CrossRef]

13. Herrmann, J.L.; Lagrange, P.H. Intracellular activity of zidovudine (3'-azido-3'-deoxythymidine, AZT) against Salmonella typhimurium in the macrophage cell line J774-2. Antimicrob. Agents Chemother. 1992, 36, 1081-1085. [CrossRef] [PubMed]

14. Peyclit, L.; Baron, S.A.; Yousfi, H.; Rolain, J.M. Zidovudine: A salvage therapy for $m c r-1$ plasmid-mediated colistin-resistant bacterial infections? Int. J. Antimicrob. Agents 2018, 52, 11-13. [CrossRef] [PubMed]

15. Hind, C.K.; Dowson, C.G.; Sutton, J.M.; Jackson, T.; Clifford, M.; Garner, R.C.; Czaplewski, L. Evaluation of a library of FDA-approved drugs for their ability To potentiate antibiotics against multidrug-resistant Gram-negative pathogens. Antimicrob. Agents Chemother. 2019, 63. [CrossRef] [PubMed]

16. Ng, S.M.S.; Sioson, J.S.P.; Yap, J.M.; Ng, F.M.; Ching, H.S.V.; Teo, J.W.P.; Jureen, R.; Hill, J.; Chia, C.S.B. Repurposing zidovudine in combination with tigecycline for treating carbapenem-resistant Enterobacteriaceae infections. Eur. J. Clin. Microbiol. Infect. Dis. 2018, 37, 141-148. [CrossRef] [PubMed]

17. Chiu, S.K.; Ma, L.; Chan, M.C.; Lin, Y.T.; Fung, C.P.; Wu, T.L.; Chuang, Y.C.; Lu, P.L.; Wang, J.T.; Lin, J.C.; et al. Carbapenem nonsusceptible Klebsiella pneumoniae in Taiwan: Dissemination and increasing resistance of carbapenemase producers during 2012-2015. Sci. Rep. 2018, 8, 8468. [CrossRef]

18. Clinical and Laboratory Standards Institute. Performance Standards for Antimicrobial Susceptibility Testing: Thirtieth Informational Supplement; Clinical and Laboratory Standards Institute: Wayne, PA, USA, 2020; Document M100-S30 CLSI.

19. Clinical Breakpoints and Dosing of Antibiotics. Available online: https://www.eucast.org/clinical_ breakpoints/ (accessed on 11 November 2020).

20. Tseng, S.P.; Wang, S.F.; Ma, L.; Wang, T.Y.; Yang, T.Y.; Siu, L.K.; Chuang, Y.C.; Lee, P.S.; Wang, J.T.; Wu, T.L.; et al. The plasmid-mediated fosfomycin resistance determinants and synergy of fosfomycin and meropenem in carbapenem-resistant Klebsiella pneumoniae isolates in Taiwan. J. Microbiol. Immunol. Infect. 2017, 50, 653-661. [CrossRef]

21. Yang, T.Y.; Wang, S.F.; Lin, J.E.; Griffith, B.T.S.; Lian, S.H.; Hong, Z.D.; Lin, L.; Lu, P.L.; Tseng, S.P. Contributions of insertion sequences conferring colistin resistance in Klebsiella pneumoniae. Int. J. Antimicrob. Agents 2020, 55, 105894. [CrossRef]

22. Kakuda, T.N.; Page, L.M.; Anderson, P.L.; Henry, K.; Schacker, T.W.; Rhame, F.S.; Acosta, E.P.; Brundage, R.C.; Fletcher, C.V. Pharmacological basis for concentration-controlled therapy with zidovudine, lamivudine, and indinavir. Antimicrob. Agents Chemother. 2001, 45, 236-242. [CrossRef]

23. Lutgring, J.D. Carbapenem-resistant Enterobacteriaceae: An emerging bacterial threat. Semin. Diagn. Pathol. 2019, 36, 182-186. [CrossRef] [PubMed] 
24. Porreca, A.M.; Sullivan, K.V.; Gallagher, J.C. The epidemiology, evolution, and treatment of KPC-producing organisms. Curr. Infect. Dis. Rep. 2018, 20, 13. [CrossRef] [PubMed]

25. Kumar, M. Colistin and tigecycline resistance in carbapenem-resistant Enterobacteriaceae: Checkmate to our last line of defense. Infect. Control. Hosp. Epidemiol. 2016, 37, 624-625. [CrossRef] [PubMed]

26. Qamar, S.; Shaheen, N.; Shakoor, S.; Farooqi, J.; Jabeen, K.; Hasan, R. Frequency of colistin and fosfomycin resistance in carbapenem-resistant Enterobacteriaceae from a tertiary care hospital in Karachi. Infect. Drug Resist. 2017, 10, 231-236. [CrossRef] [PubMed]

27. Li, Y.; Sun, Q.L.; Shen, Y.; Zhang, Y.; Yang, J.W.; Shu, L.B.; Zhou, H.W.; Wang, Y.; Wang, B.; Zhang, R.; et al. Rapid increase in prevalence of carbapenem-resistant Enterobacteriaceae (CRE) and emergence of colistin resistance gene $m c r-1$ in CRE in a hospital in Henan, China. J. Clin. Microbiol. 2018, 56. [CrossRef] [PubMed]

28. Du, H.; Chen, L.; Tang, Y.W.; Kreiswirth, B.N. Emergence of the mor-1 colistin resistance gene in carbapenem-resistant Enterobacteriaceae. Lancet Infect. Dis. 2016, 16, 287-288. [CrossRef]

29. Malchione, M.D.; Torres, L.M.; Hartley, D.M.; Koch, M.; Goodman, J.L. Carbapenem and colistin resistance in Enterobacteriaceae in Southeast Asia: Review and mapping of emerging and overlapping challenges. Int. J. Antimicrob. Agents 2019, 54, 381-399. [CrossRef]

30. Doleans-Jordheim, A.; Bergeron, E.; Bereyziat, F.; Ben-Larbi, S.; Dumitrescu, O.; Mazoyer, M.A.; Morfin, F.; Dumontet, C.; Freney, J.; Jordheim, L.P. Zidovudine (AZT) has a bactericidal effect on enterobacteria and induces genetic modifications in resistant strains. Eur. J. Clin. Microbiol. Infect. Dis. 2011, 30, 1249-1256. [CrossRef]

31. Jordheim, L.P.; Durantel, D.; Zoulim, F.; Dumontet, C. Advances in the development of nucleoside and nucleotide analogues for cancer and viral diseases. Nat. Rev. Drug Discov. 2013, 12, 447-464. [CrossRef]

32. Zhou, Y.F.; Liu, P.; Dai, S.H.; Sun, J.; Liu, Y.H.; Liao, X.P. Activity of tigecycline or colistin in combination with zidovudine against Escherichia coli harboring tet $(\mathrm{X})$ and mor-1. Antimicrob. Agents Chemother. 2020. [CrossRef]

33. Lin, Y.W.; Abdul Rahim, N.; Zhao, J.; Han, M.L.; Yu, H.H.; Wickremasinghe, H.; Chen, K.; Wang, J.; Paterson, D.L.; Zhu, Y.; et al. Novel polymyxin combination with the antiretroviral zidovudine exerts synergistic killing against NDM-producing multidrug-resistant Klebsiella pneumoniae. Antimicrob. Agents Chemother. 2019, 63, e02176-18. [CrossRef]

34. Falagas, M.E.; Voulgaris, G.L.; Tryfinopoulou, K.; Giakkoupi, P.; Kyriakidou, M.; Vatopoulos, A.; Coates, A.; $\mathrm{Hu}, \mathrm{Y}$;; Colistin-Azidothymidine Hellenic Study Group. Synergistic activity of colistin with azidothymidine against colistin-resistant Klebsiella pneumoniae clinical isolates collected from inpatients in Greek hospitals. Int. J. Antimicrob. Agents 2019, 53, 855-858. [CrossRef]

35. Hu, Y.; Liu, Y.; Coates, A. Azidothymidine produces synergistic activity in combination with colistin against antibiotic-resistant Enterobacteriaceae. Antimicrob. Agents Chemother. 2019, 63. [CrossRef] [PubMed]

36. Elwell, L.P.; Ferone, R.; Freeman, G.A.; Fyfe, J.A.; Hill, J.A.; Ray, P.H.; Richards, C.A.; Singer, S.C.; Knick, V.B.; Rideout, J.L.; et al. Antibacterial activity and mechanism of action of $3^{\prime}$-azido-3' -deoxythymidine (BW A509U). Antimicrob. Agents Chemother. 1987, 31, 274-280. [CrossRef] [PubMed]

37. Loose, M.; Naber, K.G.; Hu, Y.; Coates, A.; Wagenlehner, F.M.E. Serum bactericidal activity of colistin and azidothymidine combinations against $m c r$-1-positive colistin-resistant Escherichia coli. Int. J. Antimicrob. Agents 2018, 52, 783-789. [CrossRef] [PubMed]

38. Schneider, E.K.; Reyes-Ortega, F.; Velkov, T.; Li, J. Antibiotic-non-antibiotic combinations for combating extremely drug-resistant Gram-negative 'superbugs'. Essays Biochem. 2017, 61, 115-125. [PubMed]

39. Wattanagoon, Y.; Na Bangchang, K.; Hoggard, P.G.; Khoo, S.H.; Gibbons, S.E.; Phiboonbhanakit, D.; Karbwang, J.; Back, D.J. Pharmacokinetics of zidovudine phosphorylation in human immunodeficiency virus-positive thai patients and healthy volunteers. Antimicrob. Agents Chemother. 2000, 44, 1986-1989. [CrossRef] [PubMed]

40. Burger, D.M.; Meenhorst, P.L.; ten Napel, C.H.; Mulder, J.W.; Neef, C.; Koks, C.H.; Bult, A.; Beijnen, J.H. Pharmacokinetic variability of zidovudine in HIV-infected individuals: Subgroup analysis and drug interactions. AIDS 1994, 8, 1683-1689. [CrossRef] [PubMed]

41. Drew, R.H.; Weller, S.; Gallis, H.A.; Walmer, K.A.; Bartlett, J.A.; Blum, M.R. Bioequivalence assessment of zidovudine (Retrovir) syrup, solution, and capsule formulations in patients infected with human immunodeficiency virus. Antimicrob. Agents Chemother. 1989, 33, 1801-1803. [CrossRef] 
42. Hoetelmans, R.M.; Burger, D.M.; Meenhorst, P.L.; Beijnen, J.H. Pharmacokinetic individualisation of zidovudine therapy. Current state of pharmacokinetic-pharmacodynamic relationships. Clin. Pharmacokinet. 1996, 30, 314-327. [CrossRef]

43. Lewin, C.S.; Allen, R.; Amyes, S.G. Zidovudine-resistance in Salmonella typhimurium and Escherichia coli. J. Antimicrob. Chemother. 1990, 25, 706-708. [CrossRef]

Publisher's Note: MDPI stays neutral with regard to jurisdictional claims in published maps and institutional affiliations.

(C) 2020 by the authors. Licensee MDPI, Basel, Switzerland. This article is an open access article distributed under the terms and conditions of the Creative Commons Attribution (CC BY) license (http://creativecommons.org/licenses/by/4.0/). 